\title{
Assessment of entrance skin doses and radiation protection for pediatric X-ray examination
}

\begin{tabular}{cc}
\hline Rozhan Ahmad Hamad Saeed* & Runak Tahir Ali** \\
\hline Abstract &
\end{tabular}

Background and objective: Entrance skin dose is the value of the radiation absorbed dose by the skin where the X-ray beam enters the patients. Assessment of entrance skin doses, specifically for pediatric radiology, is very crucial as the children are dividing cells rapidly and are more sensitive to radiation than adults. Their cells can be easily damaged by excessive radiation dose. This study is considered as an attempt to evaluate the effects of diagnostic X-ray on pediatric patients throughout measuring the entrance skin doses and hematological parameters for pediatric patients. Ways of protecting themselves from X-ray hazards is also included.

Methods: A case-control study was used to collecting the data for 70 pediatric patients from October 2015 to August 2016 at Radiology Departments of five governmental hospitals throughout Hawler city the capital of Kurdistan Region- Iraq. Pediatric patients aged between ( 1 day - 6 years) they were divided into case and control group by which 40 of them had got diagnostic X-ray examination as (case group) and 30 of them had not had past history of taking X-rays as (control group). Entrance skin dose was measured indirectly via parameters such as a focus on skin distance, tube voltage (KV) and tube current (mAs) in an arithmetical equation.

Results: High level of entrance skin doses were received by pediatric patients in this study. Also, it was found that diagnostic X-ray has effects on pediatrics white blood cells and platelets with the significant difference between case and control group and $p$-values $(<0.001$ and 0.006$)$ respectively.

Conclusion: Entrance skin doses levels received by pediatric patients in this study was higher than other studies level and then pediatric patients will be at risk if they are exposed to unnecessary exposure to ionizing radiation. It is important to focus on improving pediatric radiography for reducing the hazards of $X$-ray radiation on pediatric patients.

Keywords: Entrance skin dose; pediatric radiology; Diagnostic X-ray; Radiation protection.

\section{Introduction}

Diagnostic X-ray imaging is an important part of nowadays worldwide healthcare. It can begin in the very early stages of life, but due to the sensitivity of children more than adults, special care should be applied. $^{1}$ Knowledge of entrance skin doses is important to formulate national diagnostic reference level for optimizing radiation protection of patients in pediatric radiology. ${ }^{2}$ Pediatric diagnostic X-ray examinations are riskier when compared to the ones carried out for adults because of their greater cell proliferation rate and long lifespan expectancy. ${ }^{3}$ United nation scientific committee on effects of atomic radiation UNSCEAR has reported that children exposed to radiation at an age below five years are two to three times more sensitive when compared with adults. ${ }^{4}$ Dose assessment in pediatric radiology should be made to enhance the optimization of the radiation protection. The international commission on radiological protection recommended that all medical exposures should be limited for radiation

* Directorate of Health, Erbil, Iraq.

** Department of Pharmacology and Biophysics, College of Medicine, Hawler Medical University, Erbil, Iraq. 
workers. Also, patients during diagnostic X-ray examinations have been highlighted by increasing knowledge of the hazards of ionizing radiation. ${ }^{5}$ The estimation of entrance skin dose (ESD) specifically in pediatric radiology is very crucial as the children dividing cells rapidly and are more radiosensitive than those of adults and they can easily be damaged by excessive radiation dose. ${ }^{6}$ This study provides the assessment of the entrance skin dose for pediatric patients and various comparisons of complete blood count parameters between radiation exposed pediatric patient and radiation unexposed pediatric patients to identify the effects of X-ray on their hematological parameters during complete blood count test. The study also provides information about radiation protection measurements.

\section{Methods}

Seventy pediatric patients were enrolled in this study in five governmental hospitals (pediatric and general) in Erbil, the capital of Kurdistan region, which had diagnostic X-ray department. The hospitals included Rapareen Hospital, Maternity Teaching Hospital, Hawler Teaching Hospital, West Erbil Emergency Hospital and Ble General Hospital. Rapareen Hospital, Maternity Teaching Hospital and Hawler Teaching Hospital were old hospitals and West Erbil Emergency Hospital and Ble General Hospital were new hospitals. Pediatric patients aged between 1 day and 6 years. They were divided into two groups. The first group included 40 pediatrics who had got diagnostic X-ray examination as (case group) and 30 of them had not had past history of taking $\mathrm{X}$-rays as (control group). The study was conducted from October 2015 to August 2016. The arithmetic equation was used for measuring the entrance skin doses for pediatric patients. During the study parameters such as $\mathrm{KVp}$, $m A s$, focus on skin distance (FSD) and $\mathrm{mm}$.Al were taken and put into the equation to find the entrance skin dose which received by pediatric patients.

$$
E S D=C\left(\frac{K V p}{F S D}\right)^{2}\left(\frac{m A s}{m m \cdot A l}\right) \ldots \ldots \ldots
$$

ESD stands for Entrance skin dose $c=$ constant $=0.2775$

$\mathrm{Kvp}=$ Applied Tube potential $\mathrm{mAs}=$ Tube current multiplied by exposure time

$\mathrm{FSD}=$ Focus to skin distance $(\mathrm{cm})$

$\mathrm{mm} \cdot \mathrm{Al}=$ thickness of Aluminum Filtration .

As the hematological process, three milliliters of blood were collected from each of the 70 participants by venipuncture in a disposable syringe and blood was transferred to a tube containing ethylene di-amine tetra acetic acid (EDTA) in a concentration of $5.4 \mathrm{mg} / 3 \mathrm{ml}$. As soon as possible Hematology analysis was performed with a hematology electronic cell counter (Medonic coulter counter). Routine hematological indices were performed involving white blood cells (WBCs) count, red blood cells (RBCs) count, hemoglobin content (HB), hematocrit (HCT\%), MCV (Mean corpuscular volume), $\mathrm{MCH}$ (Mean corpuscular hemoglobin), RDW (Red blood cells distribution width), platelet (PLT) count, MPV (Mean platelet volume) and PDW (platelet distribution width). Statistical evaluation was performed using statistical t-tests by the SPSS 23 program. Results were considered statistically significant when the $P$ value was $\leq 0.05$.

\section{Results}

All the information for 40 pediatric patients in case group which have undergone diagnostic X-ray examination with age from ( 1 day to 6 years) participated in the study are shown in Table 1 . Also, Table 2 shows the differences in hematological parameters between case and control group for pediatric patients take different diagnostic X-ray examination like abdomen, chest, elbow, foot, hand, pelvis and skull in the five governmental hospitals. 
Assessment of entrance skin doses and radiation ....... Z Zanco J. Med. Sci., Vol. 21, No. (3), December, 2017 https://doi.org/10.15218/zjms.2017.046

Table 1: Demographic data for pediatric patients and their $\mathrm{X}$-ray examination.

\begin{tabular}{lccc}
\hline Parameters & \multicolumn{4}{c}{$\begin{array}{c}\text { Ranges } \\
\text { Means }\end{array}$} \\
\hline Age & Less than 1 month & 1 month - 1year & $(>1-6)$ years \\
Weight/ Kg & $2.5-4.1$ & $5.5-10$ & $10-24$ \\
& 3.3 & 7.75 & 17 \\
Height/ $\mathrm{m}$ & $0.41-0.63$ & $0.64-0.72$ & $0.73-1.07$ \\
$\mathrm{BMI}\left(\mathrm{Kg} / \mathrm{m}^{2)}\right.$ & 0.52 & 0.68 & 0.9 \\
& $14.87-10.33$ & $13.42-19.29$ & $18.76-20.96$ \\
$\mathrm{KV}$ & 12.2 & 16.76 & 19.86 \\
& $45-55$ & $48-58$ & $55-65$ \\
$\mathrm{mAs}$ & 50 & 53 & 60 \\
& $3.2-4.5$ & $3.2-5$ & $4-8$ \\
$\mathrm{FSD} / \mathrm{cm}$ & 3.85 & 4.1 & 6 \\
$\mathrm{~mm} . \mathrm{Al}$ & $87-95$ & $84-90$ & $80-90$ \\
No. X-ray & 91 & 87 & 85 \\
$\mathrm{ESD} / \mathrm{mGy}$ & $1-1.61$ & $1-1.61$ & $1-1.61$ \\
& 1.305 & 1.305 & 1.305 \\
& 1.20 & 2.08 & 2.55 \\
& $0.24-0.26$ & $0.29-0.36$ & $0.52-0.72$ \\
\hline
\end{tabular}

Table 2: Differences in blood parameters between pediatric case and control group.

\begin{tabular}{llcccc}
\hline Groups & & No & Mean & Standard Deviation & $P$ value \\
\hline WBC & Cases & 40 & 7.660 & 0.972 & $<0.001$ \\
$10^{3} / \mu \mathrm{l}$ & Control & 30 & 9.747 & 1.390 & \\
$\mathrm{RBC}$ & Cases & 40 & 4.853 & 0.451 & 0.958 \\
$10^{6} / \mu \mathrm{l}$ & Control & 30 & 4.859 & 0.474 & \\
$\mathrm{HGB}$ & Cases & 40 & 13.135 & 1.868 & 0.663 \\
$\mathrm{~g} / \mathrm{dl}$ & Control & 30 & 12.940 & 1.822 & \\
$\mathrm{HCT}$ & Cases & 40 & 39.578 & 7.799 & 0.729 \\
$\%$ & Control & 30 & 38.963 & 6.922 & \\
$\mathrm{MCV}$ & Cases & 40 & 81.483 & 9.150 & 0.850 \\
$\mu \mathrm{m}^{3}$ & Control & 30 & 81.073 & 8.793 & \\
$\mathrm{MCH}$ & Cases & 40 & 28.233 & 3.240 & 0.654 \\
$\mathrm{pg}$ & Control & 30 & 27.890 & 3.084 & \\
$\mathrm{RDW}$ & Cases & 40 & 13.045 & 1.334 & 0.892 \\
$\%$ & Control & 30 & 13.000 & 1.383 & \\
$\mathrm{PLT}$ & Cases & 40 & 334.300 & 50.803 & 0.006 \\
$10^{3} / \mu \mathrm{l}$ & Control & 30 & 379.500 & 73.638 & 0.753 \\
$\mathrm{MPV}$ & Cases & 40 & 8.543 & 0.999 & \\
$\mu \mathrm{m}^{3}$ & Control & 30 & 8.620 & 1.029 & 0.260 \\
$\mathrm{PDW}$ & Cases & 40 & 12.385 & 1.479 & \\
$\%$ & Control & 30 & 12.877 & 1.985 & \\
\hline & & & & & \\
\hline
\end{tabular}




\section{Discussion}

Weights of pediatric patients considered in this study ranged between $(2.5-24) \mathrm{kg}$. These weights are nearly similar to the age group of Suliman and Elshiek hstudy ${ }^{8}$ by which their weights were ranged from $(2.4-34) \mathrm{kg}$. Age and BMI factors are expected to influence the value of ESD received by pediatric patients. In this study both of age and BMI with statistically significant correlation $(P<0.001)$ affected the entrance skin dose received by pediatric patients. This is similar to the findings in a study reported by Suliman andElshiekh $^{8}$ that similar correlation coefficient analysis was performed on dose related parameters. While comparing this study with others, it was found that the mean tube voltage of used for pediatric patients was lower than the study stated by Huda and Gkanatsios ${ }^{9}$ and nearly similar with the study stated by Omolala and Bidemi. $^{10}$ Generally, it can be seen that the exposure parameter used for pediatric patients comprises of low voltage (45- 65 $\mathrm{kVp})$ and high mAs (3.2 - $8 \mathrm{mAs})$ instead of high voltage $(60-120 \mathrm{kVp})$ and low $\mathrm{mAs}(2-7 \mathrm{mAs})$ as reported in literature. ${ }^{11}$ This implies that the quantity of incident radiation is higher while it's penetrating energy is low. The mean ESD received by pediatric patients in the age group between 1 - 6 years was between $(0.52-0.72$ mGy) during chest, abdomen, pelvis, hand, elbow, foot and skull examination. Generally, the mean ESD received by all pediatric patient in all age groups considered were on the high side when compared with ESD reported in literatures namely, $(0.077-0.550 \mathrm{mGy})^{11}$ and $(0.060$ $-2.010 \mathrm{mGy})^{9}$ and received from different $\mathrm{X}$-ray examinations that were common to pediatric patients of similar age groups. It was found that the entrance skin doses level received by the pediatric patients in this study were higher than other studies levels ${ }^{1,6,12}$ as demonstrated in Table 3 The justification may be due to the fact that the radiographers didn't use ALARA principle as low as reasonably achievable for the diagnostic X-ray examinations or X-ray machines was manufactured with lower engineering technology and gave higher doses than need. In pediatric radiology, it has been recognized that children have higher average risks of developing cancer compared with adults receiving the same dose of ionizing radiation. The longer life expectancy in children allows more time for any harmful effects of radiation to manifest, and developing organs and tissues are more sensitive to the effects of radiation. ${ }^{3}$ The most radiosensitive organs in children are bone marrow, thyroid gland, breast, brain and skin. $^{7}$ Table 3 shows the comparison between the current study and other studies. ${ }^{1,7,11-13}$ Table 2 also shows that the diagnostic X-rays have a high effect on pediatrics white blood cells and platelets with a statistically highly significant difference between pediatrics having diagnostic $X$-rays and pediatrics not having diagnostic $X$-rays and a $P$ value $<0.001$ and 0.006 , respectively. A white

Table 3: Comparison between Pediatric Entrance Skin Doses.

\begin{tabular}{lcccccc}
\hline Organs & $\begin{array}{c}\text { This study } \\
\mathbf{2 0 1 6}\end{array}$ & $\begin{array}{c}\text { Eljak and Ayad... } \\
\mathbf{2 0 1 5}\end{array}$ & $\begin{array}{c}\text { Osman } \\
\text { and Elzaki... } \\
\mathbf{2 0 1 3}\end{array}$ & $\begin{array}{c}\text { Ademola } \\
\text { and Obed... } \\
\mathbf{2 0 1 3}\end{array}$ & $\begin{array}{c}\text { NRPB } \\
\mathbf{2 0 0 0}\end{array}$ & $\begin{array}{c}\text { EC } \\
\mathbf{1 9 9 6}\end{array}$ \\
\hline Abdomen & 0.72 & 0.62 & 0.35 & 0.31 & none & 10 \\
Chest & 0.62 & 0.2 & 0.3 & 0.111 & 0.2 & 0.3 \\
Elbow & 0.25 & 0.34 & none & None & none & none \\
Foot & 0.27 & 0.21 & 0.38 & None & none & none \\
Hand & 0.24 & 0.25 & 0.24 & None & none & none \\
Pelvis & 0.68 & 0.63 & none & 0.57 & 4 & 10 \\
Skull & 0.71 & 0.69 & 0.38 & 0.66 & 3 & 5 \\
\hline
\end{tabular}


blood cell containing nucleus and DNA and it is considered to be the prime target of radiation action in the cell that's why WBCs are more affected by radiation than other cells. ${ }^{14}$ Other blood parameters like RBC, HGB, HCT, MCV, MCH, RDW, MPV and PDW are not affected by diagnostic X-rays with p-value $(0.958,0.663,0.729$, $0.850,0.654,0.892,0.753$ and 0.260 ) respectively. It is shown that the diagnostic X-rays had a destructive effect on WBC immune cells with functional impairment. The effects of exposure to ionizing radiation depend on the age at which exposure occurs. Therefore, close attention should be paid to improve the diagnostic information and to reduce the children doses as much as possible. ${ }^{15}$ For protection issue in pediatric radiology, radiologists should be quite aware of the radiation risks of diagnostic radiology and work skillfully to keep patient's radiation exposure from diagnostic radiology as low as reasonably possible while achieving the required image quality and medical benefit. ${ }^{7}$ There was lack of protection equipment nearly in all five hospitals. This lack of protective equipment in diagnostic $X$ -ray departments and this return to several reasons including, security conditions being experienced by the country, the lack of periodic preventive maintenance by staff and practitioners who specialize in this field and the lack of the QC performances in those facilities. In some cases, the cause may also be by patients to the lack of public awareness of the general public in particular. Furthermore, Canadian-Health ${ }^{16}$ recommended utilizing the protective body aprons with operating potential of up to 150 $k V p$ should provide attenuation equivalent to at least $0.5 \mathrm{~mm}$ of lead.

\section{Conclusion}

The present study concludes that the entrance skin doses levels received by the pediatric patient were higher than the other studies levels and this had effects on pediatrics WBC and PLT with a highly significant difference between case and control group. Unnecessary exposure to ionizing radiation is of great concern in pediatric patients

\section{Conflicts of interest}

The authors report no conflicts of interest.

\section{References}

1. Osman H, Elzaki A, Elsamani M, Alzaeidi J, Sharif K, Elmorsy A, Assessment of Pediatric Radiation Dose from Routine X-Ray Examination: A Hospital Based Study, Taif Pediatric Hospital. SJAMS 2013; 1(5):511-5.

2. Olowokere CJ, Babalola IA, Jibiri NN, Obed RI, Bamidele L, Ajetumobi EO. A preliminary radiation dose audit in some Nigerian Hospitals: Need for determination of National Diagnostic Reference Levels (NDRLs). Pacific JSCl Tech 2012; 13(1):487-95.

3. Khong PL, Ringertz $\mathrm{H}$, Donoghue $\mathrm{V}$, Frush $\mathrm{D}$, Rehani $\mathrm{M}$, Appelgate $\mathrm{K}$, et al radiological protection in pediatric diagnostic and interventional radiology. ICRP publication 121. Elsevier Ltd 2013; 42(2):1-63.

4. United Nations Scientific Committee on Effects of Atomic Radiation (UNSCEAR). Sources and Effects of lonizing Radiation. Report to the General Assembly. New York; 2000. Vol 1.

5. Recommendations of the International Commission on Radiological Protection. ICRP, Stem cell biology with respect to carcinogenesis aspects of radiological protection. Publication 131. Annals ICRP 2015; 44(3-4).

6. Atalabi OM, Akinlade BI, dekanmi AJ. Estimation of the Risk of Cancer Associated with Pediatric Cranial Computed Tomography. BJMMR 2015; 9(10):1-7.

7. Eljak SNA, Ayad CE, Abdalla EA, Evaluation of Entrance Skin Radiation Exposure Dose for Pediatrics Examined by Digital Radiography at Asser Central Hospital-KSA. Open Journal of Radiology 2015; 5:125-30.

8. Suliman II, Elshiekh HA, Radiation in paediatric X-ray examinations in Sudan. Rad Prot Dosim 2008; 132(1):64-72.

9. Huda W, Gkanatsios NA, Botash RJ, Botash AS Pediatric effective doses in Diagnostic Radiology. Available: http://www.nersp.osg.ufl.edu/nikos/ downloads.comp, Accessed 7 November. 2012.

10. Omolola M.A, BidemilA, Ademola JA, Olutayo AS. Entrance Surface Dose from Pediatric Diagnostic X-ray Examinations in a Developing World Setting: Are We 'ALARA Principle'Compliant?,BJMMR 2013; 3(4):2288-98.

11. European Union. European Commission. Directorate-General XII-Science, R. and Development, European guidelines on quality criteria for diagnostic radiographic images in paediatrics; 1996. Office for Official Publications of the European Communities. EUR 16261. 
12. Ademola AK, Obed RI, Adejumobi CA, Abodunrin OP, Alabi OF, Oladapo MA. Assessment of Entrance Skin Dose in routine X-ray examinations of chest, skull, abdomen and pelvis of children in five selected hospitals in Nigeria. IOSR JAPH 2013; 5(2):47-50.

13. National Radiological Protection Board (NRPB), National Protocol for Patient Dose Measurements in Diagnostic Radiology. Report of the working party of the institute of physics science; 2000.

14. Devi PU, Nagarathnam A, Rao BS. Radiation Physics, Introduction to radiation biology. New Delhi: B. I. Churchill Livingstone Pvt Ltd; 2000.

15. Mohammed MR, Abdulateef SM, Dawood NA, Taher, MG, JaburShA, Alwain AH. Effects of Radiation on the Hematological Parameters in X-Ray Technicians: A Case-Control Study. JPMS J Pioneer Med Sci 2014; 4(2):85-8.

16. Canadian-Health, X-ray Equipment in Medical Diagnosis Part A: Recommended Safety Procedures for Installation and Use. Healthy Environments and Consumer Safety Branch. $\mathrm{CMH}$ 1999. 